\title{
7. Student reporting abroad: An international programme called Journalism Reporting Field Trips
}

ABSTHRACI

A programme organised by the author for journalism students to do practical work overseas has seen small groups engaged in intercultural learning and working as foreign correspondents for campus-based media outlets. Since 2000, 60 students have joined nine tours of 10-20 days in nine countries of Europe and the Asia-Pacific region. They obtain credit for a full elective subject, e.g. an individual study unit, and may negotiate additional credits. The project's rationale was that while practice focuses the mind on essential communication tasks, practice in distant and unfamiliar settings intensifies the experience. It replicates journalistic practice of overseas correspondents encountering 'high risk and high returns': more difficulty, more headlines and colour. This practice dovetails with increasing internationalisation of the curriculum. A literature has been consulted identifying main pedagogical arguments for study abroad, and present day demands on the academy. Leading researchers in this field, viz Jane Knight propose 'non-ideological' definitions of internationalised education as a process responding to 'real world' demands. The investigation concludes that such programmes can occupy a valuable place in core curricula; relate to increasing demand for 'real world' learning and internationalisation, and can be integrated into degree structures without undue stain on resources.

Keywords: field trips, foreign correspondents, intercultural learning, international curricula, student reporting

\section{LEE DUFFIELD}

Queensland University of Technology

DVANCED level journalism students have been going to other
countries for short-term stays to do course work as foreign
correspondents on campus-based media outlets, under a programme 
called Journalism Reporting Field Trips. The project is organised in the context of a broader scheme for internationalisation of the curriculum, which in turn belongs to the global movement for internationalisation in Higher Education.

This article reports on the students' experience in a learning and teaching project which enacts the principles of internationalisation. The project, in operation since 2000 , provides them with an opportunity to do practical work overseas as part of their course work. It is set up to provide the dual benefits of intensified skills development in the field and inter-cultural experience appropriate to the demands of their intended profession.

In the method of research; the work reported on here entailed: (a) an extensive review of literature in the field of internationalisation in Higher Education; (b) observation by the researcher during engagements overseas on behalf of the overseas office of the university, which included consultations with staff of universities and educational recruitment consultants, and attendance at a conference of the European Association of International Education (EAIE; Basel, September 2006); and (c) observation and consultation with participants in the nine Journalism Reporting Field Trips conducted since 2000, including observations made while travelling with groups on four occasions.

\section{Internationalisation in Higher Education}

Internationalisation is a response to intensification of global economic activity, movement of people and communications. Universities have moved to rationalise use of resources by enabling students to transfer in from overseas to partake of their specialised offerings including the opportunity for many to learn in English. They have declared an intention to prepare students for professional practice anywhere in the world. They have placed a high value on intercultural experience in students' preparation for life in a global economic setting. They have realised the economic advantages to themselves if they can become major providers of international services. Many universities accordingly have adapted their enrolments procedures and marketing to facilitate recruitment of international students. University degree programmes have begun moving decisively towards more standardised structures, e.g. the 'Bologna' process in Europe (Duffield, 2007).

A literature on internationalisation in higher education has concentrated on finding good working definitions for the process, and on describing and 
evaluating activities committed in its name. One leader in the field, Knight (Knight, J., 2005a, 2005b) emphasises direct links between internalisation programmes and general trends in higher education, including: the growth of alternate electronic delivery modes both domestically and internationally; the increase in international academic mobility of students, professors and programmes, and the limited budget capacity (or political will) of government to meet the increasing demand for higher education (Knight, J., 2003, in Breton \& Lambert, p. 82)

Internationalisation is seen as a process which brings together different elements, always accommodating change: 'Internationalisation at the national, sector, and institutional levels is defined as the process of integrating an international, intercultural, or global dimension into the purpose, functions or delivery of postsecondary education' (Knight, J., 2003a, p. 1). De Wit provides reinforcement, adding in the key phenomenon of use of English language, defining in these terms: 'The internationalisation of higher education refers to the process of integrating an international/intercultural dimension into the teaching, research and service functions of the academic institution', and, 'the increasingly international focus of higher education is dialectically related to the present globalisation and regionalisation of our societies and markets. As a result the importance of quality assessment of internationalisation strategies has grown, international academic consortia and networks have emerged, and English has been firmly established as the international language in higher education' (de Wit, 2002).

Arguments for internationalisation on a more definitely ideological or theoretical base persist. For instance it may be said that study abroad as intercultural learning is to be valued for providing useful skills and better human empathy, in equal portions; or it can be seen as valuable in strictly pedagogical terms, offering vivid experience to reinforce learned principles. However, these propositions have been overtaken in a kind of fait accompli whereby educational practice responds directly to immediate and overbearing demands of the material world. As Knight says, the relationship between internationalisation of education and globalisation is 'dynamic', governed by the latter, so that 'a non-ideological definition of globalisation is adopted ... The discussion does not centre on the globalisation of education. Rather, globalisation is presented as a process impacting [on] internationalisation' (Knight, J., 2003a, pp. 2-3). 


\section{Responses of governments and universities}

Internationalisation has become a chief policy concern of governments and their higher education systems, where there is now participation on a mass scale. Demand for education is certainly high without precedent in a 'new' economy favouring high expertise, adding to pressure on government resources (Knight, J., 2003b, p. 95). The scale of such business has warranted making trade in education a substantial part of the World Trade Organisation's current (suspended) round of debates on international commerce, under GATS (General Agreement on Trade in Services). One figure on the value of this business: the OECD estimated 1999 trade in educational services at US\$30-billion (Knight, J., 2003b, p. 84).

A range of offerings has emerged: transnational education where learners are located outside the country of the awarding institution; crossborder education where teachers, learners, programmes or institutions cross a national jurisdictional border; and borderless education that refers to crossing conceptual as well as spatial borders, e.g. interdisciplinary programmes. This takes in the many practices found under internationalisation policies, for instance programmes offered jointly by universities and other providers; curriculum mergers like a double degree programme, or short courses; study provided at home university campuses or at overseas learning centres; or programmes offered entirely on line. (Knight, J., 2003b, p. 85) Breton and others express concern about the generation of a 'market culture' within universities around the trade in services, saying there should be managed coordination of public and private interests (Breton, in Breton \& Lambert, 2003, pp. 26, 32).

Institutions are made to feel acutely that they must keep pace with a dynamic world environment. Australian universities have acted in conformity with government policy strongly requiring an internationalised approach. Goulter, for the AVCC (Goulter, 2006), has described internationalisation as becoming 'critical' to Australian education, and trade, since 2000. He identified new Australian government policy favouring 'two-way internationalisation', foreshadowing a national programme for assisting international students and new loans for Australians to study abroad. The AVCC had identified a target of 20 percent of Australian students to study overseas as part of their course by 2020 .

The literature under review here sees outcomes being set for higher education in terms of world-wide professional communities: graduates 
obtaining credentials and abilities for life in an open and informationbased, service orientated economy. Leopold and Mercado (2006) have provided an inventory of now standard concerns of internationalised higher education, represented in the literature on the subject. These are: provision of cross-cultural, international content for learning programmes; the issue of marketing or 'franchising of academic programmes'; development and use of universal competency measures; internationalisation of staff, through use of overseas staff, or universities causing their own staff to 'go and participate', and provision of 'internationalisation at home' (where, in Britain, 60-80 percent of students still do not go abroad to study at all). The writers consider literature on objectives, (e.g. Bremer \& Van Wende, 1995; Caruana 2004; Aulakh et al 1997) to include the idea, a watchword for university prospectus brochures now, that graduates will be capable of working in their professions anywhere in the world, i.e. working successfully 'in a multi-cultural context' or 'capable of solving problems in a variety of locations'.

\section{Foundational ideas and practices}

Internationalisation became an object of much study as it gathered momentum during the 1990s, presenting a picture of change in the world at large-in turn causing wide-ranging and deep changes in the organisation of universities' work. The literature provides a general description of the universities' options and initial responses. A useful paradigm was developed by two Dutch researchers, van Dijk and Meijer. Their so-called 'internationalisation cube' matches two sets of variables: aims are judged on a continuum of central and marginal to university objectives; activities are situated on a continuum of structured to ad hoc. (The cube is then complicated with the addition of other variables, 'dimensions', called policy, support and method of implementation). It gives an indication of the issues in play and typical stratagems followed by universities, which commonly start with the more marginal and ad hoc projects. (Van Dijk \& Meijer, 1999).

\section{Other themes identified in the initial research on internationalisation:}

Globalisation of the economy with expanded trade in goods and services is demanding change in the professions, (Johnston, 1993). Universities have responded with programmes that commonly start by building on what 
exists, amending the existing curriculum. Typically they increase student exchange programmes and field experience abroad; increase foreign languages teaching, and strengthen international and area studies in subject content. However, there is inbuilt pressure in the situation, to develop it. 'Usually the advice is that it starts with a simple project of exchanges that do not hinder the continuation of core business ... The goal is that added value is established by the activities, which impacts on regular arrangements'. After the phase of 'testing the ground', activities could become more developed. 'In practice this usually implies more complex projects and partnership agreements, which outgrow the original grant schemes and imply involvement of private enterprises ... Internationalisation has to become part of core business to survive.' (Hoekzema, 1995).

There are different levels of commitment or styles in internationalisation, region by region. For example undergraduate courses in the United States would give limited international experience but the representation of American $\mathrm{PhD}$ students abroad would exceed general levels. Australian and New Zealand participation levels almost set the mean, being generally rather high, even at an early stage for the internationalisation movement. Asian institutions have not been making large commitments to student mobility but Hong Kong and Singapore emphasised use of imported academic staff. Activity in Europe was overwhelmingly in the ambit of EU integration programmes (ERASMUS, SOCRATES) or technical assistance programmes for the former Soviet bloc; activities there later dominated by debate and restructuring on the Bulogna model. (Altbach, Peterson, 1998).

Academic staff development was emphasised at several points, both to improve preparation and practice, and for economy - students move on, staff stay, so the benefits of an investment will be better preserved. International students would become valued for cultural diversity, with a recommended minimum of 10 percent enrolment.(Kelleher, 1995). Diverse course structures have continued to be tried. Universities with an advanced commitment to internationalisation will provide it as a programme integrated with units generally, and in the form of specialised units. (Kwok, 1994).

There has been a continuing interest in trying to ensure the experiences of an internationalisation programme will provide for deeper learning:

'Internationalisation and globalisation of communication will demand quite new kinds of dispositions, attitudes and skills, which go beyond 
the relatively simple issues of learning a number of languages, though that is an important aspect ...A curriculum will have to make available to its students the resources for communication which reflect global requirements ... Harmonious productive engagement with different cultures in one's own locality will demand attention to communication in quite new ways. (Kress, 1996)

An Australian Vice-Chancellors' Committee and Business Council Round Table resolved that:

commercial, industrial and business concerns, while needing and valuing such skills as literacy, numeracy, scientific and technical skills, also put a premium upon such values as citizenship, sympathy, justice and humanity. Here the emphasis changes into the need for an upgrading of communication skills and inter-personal skills ... (Aspin, 1993)

In this vein traditional liberal emphases in education on cultivating the individual for versatility are asserted, through 'merging critical thinking with international content', and so 'international education does not require a completely new curriculum' (Kelleher, 1995).

Cultural awareness and cultural learning have come to be recognised as centrally important in the educational process. There is talk of a 'sea change in corporate cultures and mindsets' in response to changes in business practice, and 'demand for executives who can manage effectively in the international environment'. The outcome is a change of emphasis for many learners.

To be educated is to have a general knowledge of a larger world... It is to have some sense of the complexities of religion and ethnicity, the nuance of power, and the forces at work in the long, complicated histories of many nations ... International education can be unsettling ... At its best however it fosters personal growth through reflection on one's assumptions, values and moral choices... It is active and experiential, putting a premium on competence - on putting what one has learned into effective practice. (Johnston, 1993)

Taking this further: 'Avoiding dogmatism - that is, making normative the values of one's perspective-lies at the heart of international education.' (Kelleher, 1995).

108 PACIFIC JOURNALISM REVIEW 14 (2) 2008 


\title{
Major trends-Study Abroad
}

Universities have expanded and embedded their internationalisation practices, as indicated above by Knight, through development of institutional arrangements like curriculum mergers with partner institutions, or cultivation of off-shore programmes and resources. This has become increasingly central, and there have been parallel advances in the marketing of university courses as products, recognising the large scale of business entailed when thousands of students come available to be recruited. As the universities have consolidated thinking and action on internationalisation, large-scale changes have occurred in research cooperation (outside the scope of this article), and teaching characteristically through the practice called Study Abroad. In a previous study - a comparative treatment of three journalism schools in Europe and Australia, and their options for collaboration on teaching - this author has described the Study Abroad option, a set of offerings heavily marketed by institutions worldwide:

\begin{abstract}
These study packages are meant to be simple and universal. Importantly, students will study for credit which can be substituted exactly for core parts of the degree at their own university. The possible extension to two semesters - in special cases even longer-means the exercise can be central not peripatetic. Places are not limited. It is a practical system removing much administration. (Duffield, 2007)
\end{abstract}

In a typical example, the Study Abroad programme at one particular university in the study was short-term, up to two semesters; had flexible choice of subjects; was relatively free of such constraints as prerequisite rules (subject to Faculties' tolerance); the international office gave special assistance, e.g. in providing information in response to home universities' requirements; places were unlimited, and the programme was full feepaying. The study by this author, an outcome of visits to the institutions and review of their curriculum documents, revealed a high degree of potential for short-term exchange in the Study Abroad model. It concluded that consortia of universities, or schools from within universities, could magnify the value of their resources through more collaborative scholarship and teaching.

Setting up, promoting and enacting a scheme such as Study Abroad has self-evident implications. For example, in the case of the undertaking to accommodate all eligible comers, the university must be highly flexible; 
it may need to take a large group of students recruited at once from one overseas source - a country or a single institution. With large numbers of international students, commonly 20 percent of enrolment in degree programmes in Australia, the commitment made by the university is large and very central to the make-up of its curriculum, and its institutional structures and functions. Policy and management are also affected, e.g. through the need to operate on negotiated, cosmopolitan standards, as seen with the reference above to quality assurance standards. Universities are encouraged increasingly to form consortia for cooperation and inter-change of students. Internationalisation involves substantial arrangements across institutions. The journalism field trips reported on here are best classed as project work; it is not the kind of undertaking that today defines or leads the internationalisation process, but there is much activity in the field, and it is easy to position this kind of work in the broad framework.

\section{Journalism Reporting Field Trips as an aspect of internationalisation}

The Journalism Reporting Field Trips programme is set in the context of a university policy which is typical now for hundreds of institutions, declaring that its graduates should be able to practice their professions anywhere in the world and that they should be able to do that with due cultural awareness. The university's main priorities and strategies became a mix of achieving business through recruitment of international students and promotion of overseas research connections; together with systematically providing growth in the range of experience available to students. It embraced study abroad and other exchange programmes. (QUT, 1999).

The field trips programme falls into a category of project activity or craft learning rather than being 'structural', e.g. not directly integral to, or dependent on any broad, university-wide changes in curricula and teaching practices. It is among several programmes found across faculties that provide supplementary experience and learning, though often integrated with course work, e.g. Built Environment students' tours in China, or Education students' school visits or practicum abroad. It was conceived, however, as a central activity, being part of a process of internationalisation of the journalism curriculum, commenced in 2000. It is today very like the kinds of activity being prescribed under Study Abroad and is compatible with Study Abroad where for instance students may in future go to a foreign university as a base for carrying out their field work overseas.

110 PACIFIC JOURNALISM REVIEW 14 (2) 2008 
The start of the programme was supported by an internal university teaching grant, for research into then-current practices in internationalisation and for preparation of learning materials, e.g. dedicated website. At the core, a new subject was inaugurated in 2001 called International Journalism, set at second-year level, providing a conceptual and theoretical base for the field work project that follows. It surveys trends in world communication, the news industry, inter-cultural issues and current issues in journalism. It provides for the interests of students unable to travel who can fill production roles. It has proved popular with increased enrolments annually.

\section{Conducting the Reporting Field Trips}

The Journalism Reporting Field Trips programme is ongoing and attached to a degree programme with some 350 students enrolled in core journalism subjects, recognised for its practical approach — teaching principles through practice. Participating in the field trips is open to undergraduates at third-year level or above, and graduate students, who go off to practice skills through working as international correspondents. (There is a dispensation for second year students to join in special cases, e.g. language and cultural affinity or life experience of the terrain). The premise is that the mind concentrates and journalism learning intensifies where it is removed from familiar home supports and assumptions. It becomes forced learning, bringing the students' attention to bear on the story of the day; the need to be well backgrounded;keepinghard deadlines; considering cultural nuances whenobtaining interviews, and the need to be able to function well while moving about in unfamiliar surrounds.

Members of the travel group each time attend prearranged briefings on their itinerary, e.g. meetings with Members of the European Parliament at Brussels; a group session with the Hong Kong legislator Emily Lau; a walk through a squatters' settlement outside Madang; a short internship at a news room in Penang. They take on a quota of stories - news reports or featuresto send home from field locations; at least three reports weekly, each for two media, is a common requirement. They have the experience of late night or early morning filing sessions from hotel rooms or borrowed radio studios, to supply campus-based media, principally a campus-based community radio outlet and online services. What must distinguish these expeditions from other learning tours or exchanges is that they follow the hectic routines experienced 
by overseas correspondents - some of the most heavily-taxed operators in terms of having to deploy good professional expertise in the field.

The work is assessed and earns course credit. In most cases the students enrol in an advanced Workplace Learning or individual study subject, equivalent to a full unit for a semester, i.e. one-eighth of one year's full-time study. Often they will supplement the experience with diary keeping on aspects of intercultural contact and communication. Preparation work includes seminars for country or language briefing, coverage planning and practical training with equipment, and briefings on current issues, then de-briefing on return to Australia, all of which demands a significant commitment of time. Usually the travel takes place during a vacation period or semester break sometimes with leave granted for a further week away during class time. The tours are for small groups and most expenses are paid by the students taking part. Costs to individuals have ranged from $\$ 1400$ for 10 days in Indonesia to $\$ 5-7000$ for three weeks in Europe. The travel project has attracted its 60 participants from the full range of journalism courses (Bachelor of Journalism degree; joint/double degree courses; Honours year; graduate courses); they are mostly undergraduates with a significant representation of graduates (12), international students (12), and students committing to the programme because of existing overseas interests including language skills.

\section{Review of the Reporting Field Trips Programme}

As a goal, this scheme that places well motivated students in foreign environments acts on the assumptions contained in the literature on internationalisation, that such experience is advantageous to learning and professional preparation in globalised society and the new world economy (Table 1). It would draw on well prepared staff, engage both Australian and international students, provide depth of learning, foster cultural awareness and empower students to make confident adjustments to demands experienced in new fields of activity. It will have experimental value, testing ways that staff and students can make a practice of internationalisation, and is compatible with broad-scale developments in internationalisation like Study Abroad.

\section{Conduct of the review and outcomes}

The reporting field trips project has been monitored to date through close 
THE PUBLIC RIGHT TO KNOW

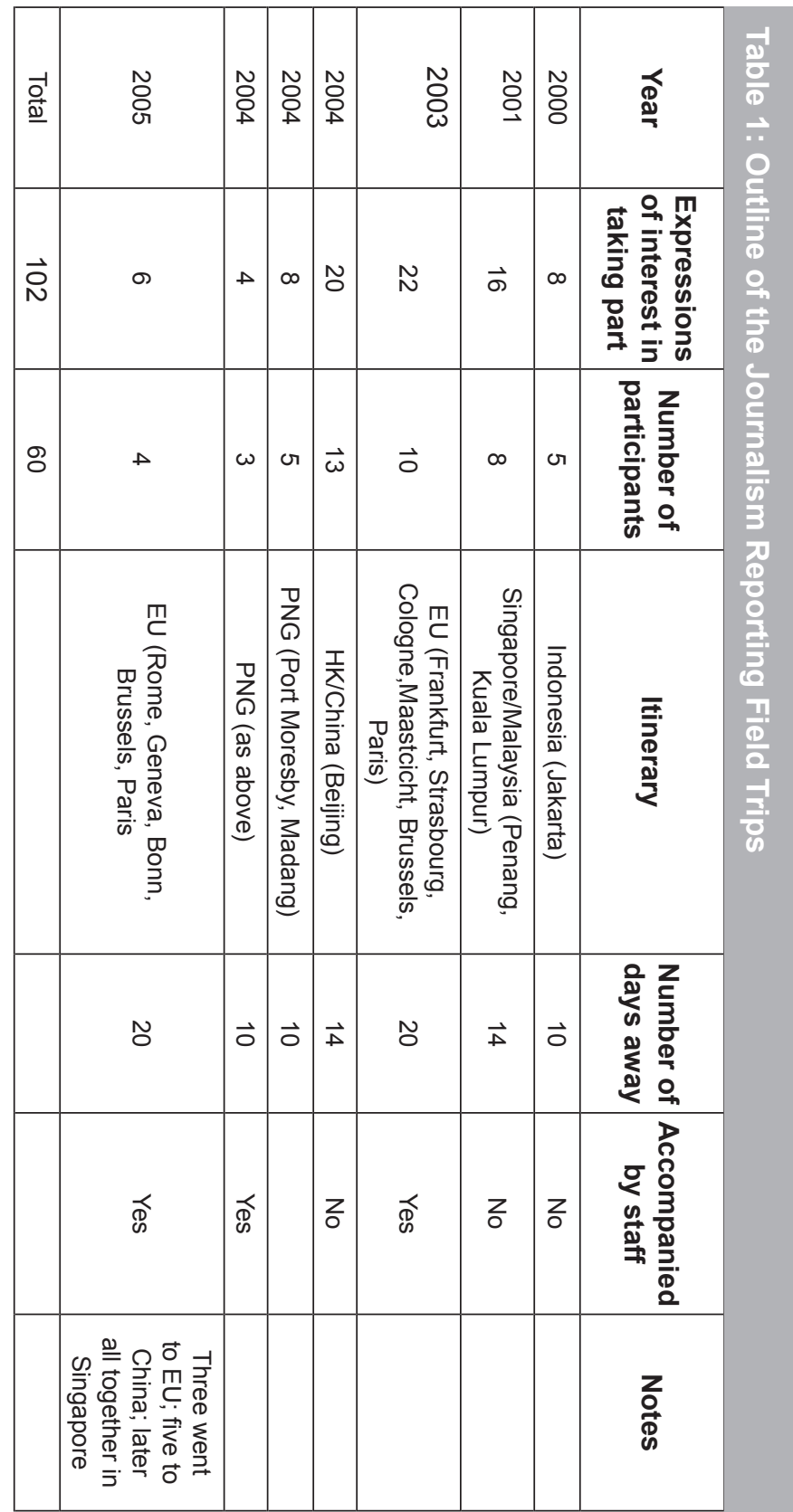


observation by the writer as an organiser of the tours, sometimes as a participant; backed by notes made during debriefings of students, with at times distribution of questionnaires.

Focus group exercises set up at the planning stage in 2000 obtained the responses of 21 Australian and international students in three groups, indicating background attitudes and expectations of the programme. The groups were strongly positive about students being able to do practical work outside of Australia. Fifteen International Students taking part broadly considered 'third country' experience would enhance their learning, saying that their current study overseas was giving them access to 'real learning' and commending it to Australian students. They said well-structured activity was important to students when outside their own country and thought local contact persons should be appointed at the working destinations. These students supported the aspect of internationalisation which would encourage students and staff alike to increase their range of experience and skill, language skills in particular. The six Australian students reported more anxiety than the International Students about language barriers, though they more easily imagined the way a relatively unstructured, more 'freelance' programme would work, and how it could be counted towards course work. These students, three of whom had already travelled abroad, expressed strong interest in cultural learning. As the programme has gone on these initial soundings proved to be a good measure of the concerns of students and a useful guide in meeting their expectations.

\section{Impacts on student learning}

Students questioned about the programme after returning to Australia almost unanimously report that they have obtained more concentrated learning from it. They state that because it was international they were caused to apply themselves much more conscientiously to learning the background to prospective news reports, e.g. understanding what the European Parliament does, or checking the biography of an interviewee. They refer to the need to concentrate hard when grappling with long-distance communications, and to take full account of intercultural differences. During debriefing eight of the 10 students from the 2003 exercise responded to a questionnaire about the programme, producing results consistent with reports obtained from all the other groups anecdotally. There was general accord that their focus on tasks 
was intensified when on the road; and that self-sufficiency was called for in the field, the importance of backgrounding on issues or cultural aspects being well demonstrated then. Responses to intercultural experience were not stated very clearly; this was a matter that the participants wanted to think about further. While attending to home audiences was the priority of the moment, students recognised also from their reading that audiences were becoming more globalised and diverse. Increasingly the task is to understand and respond to audiences across an intercultural field. As for grasping principles of communication that would underlie their practical work, the students reported a heightened sense of striving to communicate with audiences in Australia, feeling conscious that the audience members would lack good backgrounding on the contents of their reports. All of the students rated the value of the programme to their individual scholarship and preparation for journalism highly at 6 or 7 on a seven-point scale.

Among outcomes, it can be inferred that the stimulus of the reporting boosts performance, as the participants return both very credible practical work in the field and substantial reflective exercises, e.g. follow-up essays in their course work subjects. The researcher can aver that the reportage rated strongly on the criteria routinely applied during praxis: sound news sense, adroit and appropriate crafting of words, sound and illustration; technical mastery, and a 'teamwork' factor measuring autonomy against any need for constant help, speed and ability to assist others. Hopefully achievement can be represented here also in an impressionistic way, through examples of work by some students with foreign languages or other skills.

One student with German language parleyed access to the gallery of the Frankfurt stock exchange to shoot overlay for a video report on the stock market; another recorded interviews with European and Australian expatriates in Southeast Asia, for radio programmes in German and English on their cultural learning; a student with French made an illustrated feature based on the Tintin museum in Brussels; three students branched off for an independent reporting trip to the threatened Three Gorges in China; a student with a nursing background reported in an expert way on the needs of health services in Papua New Guinea, following up with a project to send donations to clinics and hospitals there; an Italian speaker made a resourceful portfolio of radio reports involving dialogue with translation, in Italy, from politics to a gelati-tasting; an Australian student obtained help from Dutch relatives 
to get a day out with the Netherlands police. Such work was frequently applied to longer-term and reflective projects. For example a student made observations and interviews at radio stations in Papua Guinea, then did the same in Brisbane and country New South Wales, for a comparative study on community broadcasting, as an Honours thesis. Another Honours student took advantage of the field trip to interview several overseas correspondents for her thesis on foreign news reporting. The broadcasts in German and English from South-east Asia were developed into a successful practice-led Masters project.

The key point here is that there has been impetus, and students have mobilised their resources to a high degree. Most of those attracted to the programme are resourceful students who have been achieving well to begin with. Yet the group is mixed, with a substantial minority in each group usually achieving in the lower Grade Point Average range, 4-5. In almost all cases students received higher grades, frequently Distinctions (6) or High Distinctions (7) for work associated with a reporting field trip. Performance is maintained or improved after field trips; the overall course grade point average for this group being rather high, at 5.7. Furthermore members of this group have done well obtaining full-time media positions or other kinds of employment they wanted, most affirming that the overseas experience was featured prominently in their curriculum vitae along with other distinctions. The researcher has been checking on the progress of the participants, and while some are still being sought Table 2 indicates a set of positive employment outcomes for 36 currently located.

Intercultural experience has been important in this programme and is a subject for future investigation, to discover what level of learning has occurred, and what the impacts may be in terms of the way that graduates from the programme will practice. Use of foreign languages is one area where participants have concentrated and recorded their thoughts. Being able to cope in a foreign language environment has been a point of anxiety and great interest to the students. They discover it is possible to manage well in most places using only English, but also encounter its limits. A message given to students as part of the promotion of this project is that language skills are highly advantageous to mass media practitioners in the globalised working environment this century. Students with language credentials are encouraged to join; they have demonstrated the advantages of being able to work outside of 


\begin{tabular}{|c|c|c|}
\hline Employment source & $\begin{array}{l}\text { Number of } \\
\text { graduates }\end{array}$ & Notes \\
\hline ABC television & 3 & \\
\hline Commercial television & 4 & \\
\hline$A B C$ radio or online & 5 & \\
\hline DW German radio and television & 2 & $\begin{array}{l}\text { One former international student } \\
\text { (IS); one Australian }\end{array}$ \\
\hline $\begin{array}{l}\text { Employment in media or other } \\
\text { specialised work overseas }\end{array}$ & 7 & $\begin{array}{l}\text { Former ISS, mostly in media } \\
\text { organisations; includes one } \\
\text { Australian in London press }\end{array}$ \\
\hline Metropolitan press & 2 & \\
\hline Other press & 4 & \\
\hline Legal practitioner & 3 & \\
\hline Other professional employment & 3 & $\begin{array}{l}\text { Writer on arts grants; government; } \\
\text { political advisor; Australian } \\
\text { business consultant in Asia }\end{array}$ \\
\hline Further study & 3 & \\
\hline Total & 36 & \\
\hline
\end{tabular}

English, especially in finding interviewees, and have been helpful to the group carrying out everyday tasks. Twenty-four of the 60 participants had a strong conversational use or better, of at least one language other than English.

Preparation for the reporting field trips takes in introductory learning of basic language and cultural mores, though by far the most common report from participants after the tour, is that they regretted not paying more attention to it and doing more of the recommended preparation. This is expressed through numerous anecdotal examples, e.g. to do with different protocols encountered for setting up contacts and addressing people, characteristics of local media in comparison with Australia, and experience meeting groups of students in universities on the itinerary. As was observed in the literature review, above, 'international education can be unsettling' (Johnson, 1993). The most positive outcome to date, in respect of cultural awareness, may be that this has been a good starting point, that the experience has raised awareness of cultural differences and has demonstrated to aspiring practitioners that they will need to address them. 
Lessons have been drawn from experience on the practicalities of running this activity; so there are now clear standards on such points as the optimum size of groups (four or five persons); best durations for trips, the number of rest days, and optimum periods to stay in one location; best communication arrangements, concerning equipment and software; the extent of detailed planning that will be required, and the number of pre-booked briefings to ensure the programme will go smoothly. Risk assessment is handled in strict compliance with published university travel requirements, and training has been adapted to address special problems, e.g. in Europe street harassment of young women walking alone. Experience has shown that where groups are not accompanied by staff, it is very helpful to engage a local mentor from a university or the news media-which is now standard practice. Students in this programme are self-recruited, responding to an annual notice that sets out the eligibility standards, and have really defined the most suitable cohort for it. The programme is flexible but clearly very suitable for advanced level students with a more developed knowledge base and existing media production skills, learned earlier in their study programme. Accordingly graduate students are well represented and among the strongest supporters of the programme, often having the benefit of a few more years background learning and general experience including previous foreign travel.

\section{Further work}

Further research is required with returning students and others, to follow up anecdotal reports about changes that have taken place as a result of the reporting fields trips experience. For example, from the body of experience that has built up, we can investigate how students may have developed their understanding of journalistic processes, and what changes will have occurred in cultural understanding. There is scope for expansion through further work on other aspects of internationalisation of the curriculum, e.g. to investigate prospects for including more language learning, cultural learning and study of global issues like human rights or international relations, in journalism programmes.

\section{Conclusions}

Internationalisation in Higher Education is an application of globalisation in business, finance and economics, knowledge creation and research, and 
social and cultural experience. It entails thorough and ongoing change on an institutional level especially in research cooperation with outside bodies and in student recruitment and teaching. Universities have set out to enhance and diversify student experience through various exchange strategies, off-shore offerings or 'borderless' teaching schemes. Internationalisation of the curriculum began on a large scale less than 20 years ago, in its various forms, from extemporised short enrichment programs ('multicultural learning' at home; familiarisation visits abroad), through to the formation of consortia to develop joint programmes and exchange students in large numbers. Large impact has been achieved already through the development of Study Abroad as a well-structured, global project organised by many institutions, each on a university-wide basis, designed to operate flexibly, to provide short-term overseas learning integrated into the core curriculum at home.

The Journalism Reporting Field Trips programme has been developed through experiment, as 'craft' activity based in one university department, to find benefit for students in the 'opening' of the world to more globalised professional practice - and so more globalised reach of experience and learning. It fits into the broad movement of major institutional change. It has proved a highly useful base for the development of knowledge of the learning and teaching process in new international settings. Through projects of this kind it is possible to get a better understanding of how overseas learning and teaching can best be managed especially at faculty level. In the case in point, it has been possible to check what is done against the yardstick of students' scholarly attainments and professional outcomes, and some assessment of the character of knowledge attained through intercultural practice. It has been possible to see what can be achieved in terms of a cost-effective deployment of university resources especially staff time and direct expenses budgets for travel. There has been an accumulation of knowledge about important aspects of implementation of programmes, e.g. to determine what is a sustainable intensity of experience for students, in terms of workload, or making provision for their security and welfare. The Journalism Reporting Field Trips project also is well geared to integrate into 'main frame', university wide internationalisation practices, expressly Study Abroad, because of its flexibility and concentration into short durations away. 


\section{References}

Altbach, P.G., and P. McGill Peterson (1998). Internationalise American higher education? Not exactly. Change, July-August 1998, 30(4): pp. 36-39.

Aspin, D.N. (1999). Quality, teacher education and internationalisation: A challenge for co-operation in teacher education. Journal of Education for Teaching, 19(2): pp. 323-331.

Breton, G. (2003). Introduction: Higher education: From internationalisation to globalisation. In Breton, G. and M. Lambert (Eds.)., Universities and globalisation: Private linkages, private trust (pp. 26-32) Paris: UNESCO

CRE (Confederation of European Union Rectors' Conferences, and the Association of European Universities), (1999, updated). The Bologna Declaration on the European Space for Higher Education: An explanation. Retrieved on 11 December 2006, from: http://ec.europa.eu/educaton/policies /edu/bologna/bologna.pdf

De Wit, H. (2002). Internationalisation of higher education in the United States of America and Europe. Westwood CT, Greenwood. Synopsis. Retrieved on 4 December 2006, from: www.greenwood.com/Greenwood_press.aspx

Duffield, L. (2007). Internationalisation in higher education, journalism, and preparation for work in the new world economy: a case study approach based on Australian and European experience, suggesting ways that journalism schools worldwide might respond to internationalising work being done by universities. In Proceedings media, education and development: The quest for new paradigms: AMIC-World Journalism Education Congress, joint conference, pp. 1-17, Singapore. See also http://eprints.qut.edu/au/view/person/Duffield,_Lee.html

Goulter, I. (2006). Higher education in Australia: Quality and transnational students. European Association for International Education (EAIE), 18th Annual Conference, Basel (papers), September.

Hoekzema, H. (1995). The management of change at systemic level: Internationalisation of education and training in the Netherlands. European Journal of Education, September, 30(3): pp. 295-302.

Johnston, J.S. Jr. (1993). Beyond borders. Liberal Education, Summer, 79(3): pp. 36-41.

Kelleher, A. (1995), One world, many voices. Liberal Education. NovemberDecember, 77(5): pp. 2-8.

Kress, G. (1996). Communication in education. Comparative Education, June, 32(2): pp. 185-197.

Kwok, C.C.Y. (1994). An empirical study on finance curriculum internationalisation. Financial Practice and Education, Fall/Winter, 4(2): pp. 35-36.

Van Dijk, H. and K. Meijer (1998-99). The internationalisation cube. European Education, Winter, 30(4): pp. 44-51.

Herbert, J. (2001). Practising global journalism. Focal Press, Oxford.

Hogeschool Utrecht (2006). ECTS guide: Incoming exchange students, 2006-2007. Utrecht, HU.

Hogeschool Utrecht, University of Applied Sciences (2006). Bachelor's and master's degree programmes, (brochure). Utrecht, HU. 
Hogeschool Utrecht (2006). Hogeschool Utrecht: Third largest university of applied sciences right at the centre of the Netherlands; (screen presentation). Utrecht, HU.

Kennis in Kaart 2005, (figures and tables on Netherlands Education) (2005). The Hague, Ministry of Education and Culture.

Knight, A. (2000). Fact or fiction? The collision of journalism values in Asia; in Kingsbury D., E. Loo and P. Payne (Eds.), Foreign devils and other journalists. Melbourne, Monash Asia Institute.

Knight, A. (1995). Reinventing the wheel: Australian foreign correspondents in Southeast Asia. Media Asia, 22(1): pp. 9-15.

Knight, J. (2005a). Borderless, offshore, transnational and cross-border education: definition and data dilemmas. Report, The Observatory on Borderless Higher Education, October 2005. Retrieved on 4 December 2006, from: www.obhe.ac.uk/products/reports

Knight, J. (2005b). Internationalisation: A changing landscape: Preliminary findings from the International Association of Universities 2005 survey on internationalisation. Centre for Comparative International and Development Education (CIDEC), Workshop and Seminar series. Retrieved on 18 December 2006, from: www.unesco.org/iau/conference/alexandria/ic_papers/J_knight.rtf

Knight, J. (2003a). Updating the definition of internationalisation, International Higher Education, Fall; Centre for International Higher Education, Boston College, Boston. Retrieved on 4 December 2008, from: www.edu/bc_org/avp/soe/cihe/newsletter/News33/text001.htm

Knight, J. (2003 b). Higher education and trade agreements: What are the policy implications? In Breton G. and M. Lambert (Eds.)., Universities and globalisation: Private linkages, private trust (pp. 85-95). Paris: UNESCO.

Larkin, J. (2006). International students as customers. In van Vugt T. and T. Rogers (Eds.)., The impact of tuition fees on international student recruitment. Utrecht: EAIE.

Leopold, J., and S. Mercado (2006). Assessing curriculum internationalisation: reflections on the experience of United Kingdom business schools. European Association for International Education (EAIE), $18^{\text {th }}$ Annual Conference, Basel (papers), September.

NUFFIC (Netherlands organisation for international co-operation in higher education) (2006). Life and study: Study in Holland 2007-2008. The Hague: NUFFIC.

OECD (Organisation for Economic Co-operation and Development) (2006). OECD work in wducation. Paris: OECD.

Oslo University College (2006). Oslo University College, Norway, (introductory brochure). Oslo, OUC.

Oslo University College (2006). Courses taught in English (brochure). Oslo, OUC. Oslo University College (2006). Journalism Studies - OUC, Media and Communication Studies - OUC, (internal program outline documents). Oslo: OUC.

Queensland University of Technology, Brisbane, (1999, May 18). Inside QUT, no. 190. 
Queensland University of Technology (2006). Study abroad guide. Brisbane: QUT. Queensland University of Technology (2006). Brisbane: QUT. Student statistics, retrieved on 17 December 2006, from: http://frp.qut.edu.au/strat/datainfo/; International academic programme, retrieved on 17 December 2006, from: www.international.qut.edu.au

Reed, G. G. (1997). Globalisation and education: The case of North Korea. Compare: A Journal of Comparative Education, June, 27(2).

Servaes, J. (2000). Introduction. In Wang G., J. Servaes and A. Goonasekera (Eds.), The communications landscape (p. 2). London: Routledge.

Van den Eijnden S., President NUFFIC, and Haaksman D., Department of International Academic relations, NUFFIC, (2006); NUFFIC (Netherlands organisation for international cooperation in higher education); Seminar for Australian universities representatives (papers), September 18, The Hague.

Van Gemert, H. and L. Meijdam (2006). To subsidise or not to subsidise: Public funding of international degree-seeking students in higher education. In van Vugt T. and T. Rogers (Eds.), The impact of tuition fees on international student recruitment. Utrecht: EAIE.

Van Vugt, T. and T. Rogers (Eds.). (2006). The impact of tuition fees on international student recruitment. Utrecht: EAIE.

Dr Lee Duffield teaches journalism at the Queensland University of Technology (QUT) and writes on news media and crisis situations globally, with special interests in mass media in Europe. He is a former editor and overseas correspondent with the Australian Broadcasting Corporation. I.duffield@qut.edu.au 